\title{
A lower bound on the number of mechanisms for discriminating fourth and higher order spatial correlations
}

\author{
John WG Seamons*, Marconi S Barbosa, Anton Bubna-Litic, Ted Maddess \\ From 24th Annual Computational Neuroscience Meeting: CNS*2015 \\ Prague, Czech Republic. 18-23 July 2015
}

The human visual system must employ mechanisms to minimize informational redundancy whilst maximizing dynamic range and maintaining that which is behaviorally relevant $[1,2]$. Previous research has concentrated on two-point correlation properties, as captured by spatial frequency and orientation tuning. There has been less research into higher-order correlations although they may inform us about cortical functioning [3]. Isotrigon textures can be used to probe the sensitivity of the human visual system. The obvious structure in isotrigons is exclusively due to $4^{\text {th }}$ and higher-order spatial correlations [4]. Thus, in order to discriminate isotrigons from noise, it is necessary to identify higher-order structure. Although artificially generated, the same structural features that give isotrigons salience also create salience in natural images [2].

Factor analysis can be used to infer the number of underlying independent neurological mechanisms which govern isotrigon discrimination. In this study, mean performance functions were calculated for two subjects using ten new isotrigons (VnL2) (Figure 1A). Two forms of factor analysis identified 3 principal factors (Figure 1B) [5]. Previous studies support that the number of mechanisms is less than 10 [6], and more likely $2-4[7,8]$. Such mechanisms may represent some combination of recursive or rectifying processes. Simple models of cortical processing, based on recursion, can discriminate isotrigons [9]. The formation of recursively applied products is physiologically plausible and can occur via dendritic back-propagation or dendritic spiking [10].
Published: 18 December 2015

\section{References}

1. Barlow H: Redundancy reduction revisited. Network 2001, 12(3):241-253.

2. Tkacik G, Prentice JS, Victor JD, Balasubramanian V: Local statistics in natural scenes predict the saliency of synthetic textures. Proc Natl Acad Sci U S A 2010, 107(42):18149-18154.

3. Victor JD: Isodipole Textures: A Window on Cortical Mechanisms of Form Processing. In Early Vision and Beyond. MIT Press;Papathomas TVC, C.; Gorea, A; Kowler, E 1995:99-107.

4. Maddess T, Nagai Y, James AC, Ankiewcz A: Binary and ternary textures containing higher-order spatial correlations. Vision Res 2004, 44(11):1093-1113.

5. Seamons JWG, Bubna-Litic A, Barbosa MS, Maddess T: A Lower bound on the Number of Mechanisms for Discriminating Fourth and Higher Order Spatial Correlations. Vision Res 2015.

6. Taylor RR, Maddess T, Nagai Y: Spatial biases and computational constraints on the encoding of complex local image structure. J Vis 2008, 8(7):19 11-13.

7. Maddess T, Nagai Y: Discriminating isotrigon textures [corrected]. Vision Res 2001, 41(28):3837-3860

8. Maddess T, Nagai Y, Victor JD, Taylor RR: Multilevel isotrigon textures. J Opt Soc Am A Opt Image Sci Vis 2007, 24(2):278-293.

9. Nagai Y, Taylor RR, Loh YW, Maddess T: Discrimination of complex form by simple oscillator networks. Network 2009, 20(4):233-252.

10. Hausser M, Spruston N, Stuart GJ: Diversity and dynamics of dendritic signaling. Science 2000, 290(5492):739-744.

doi:10.1186/1471-2202-16-S1-P154

Cite this article as: Seamons et al:: A lower bound on the number of mechanisms for discriminating fourth and higher order spatial correlations. BMC Neuroscience 2015 16(Suppl 1):P154.

\footnotetext{
* Correspondence: john.seamons@anu.edu.au

Eccles Institute for Neuroscience, John Curtin School of Medical Research, ANU, Canberra, ACT 0200, Australia
} 


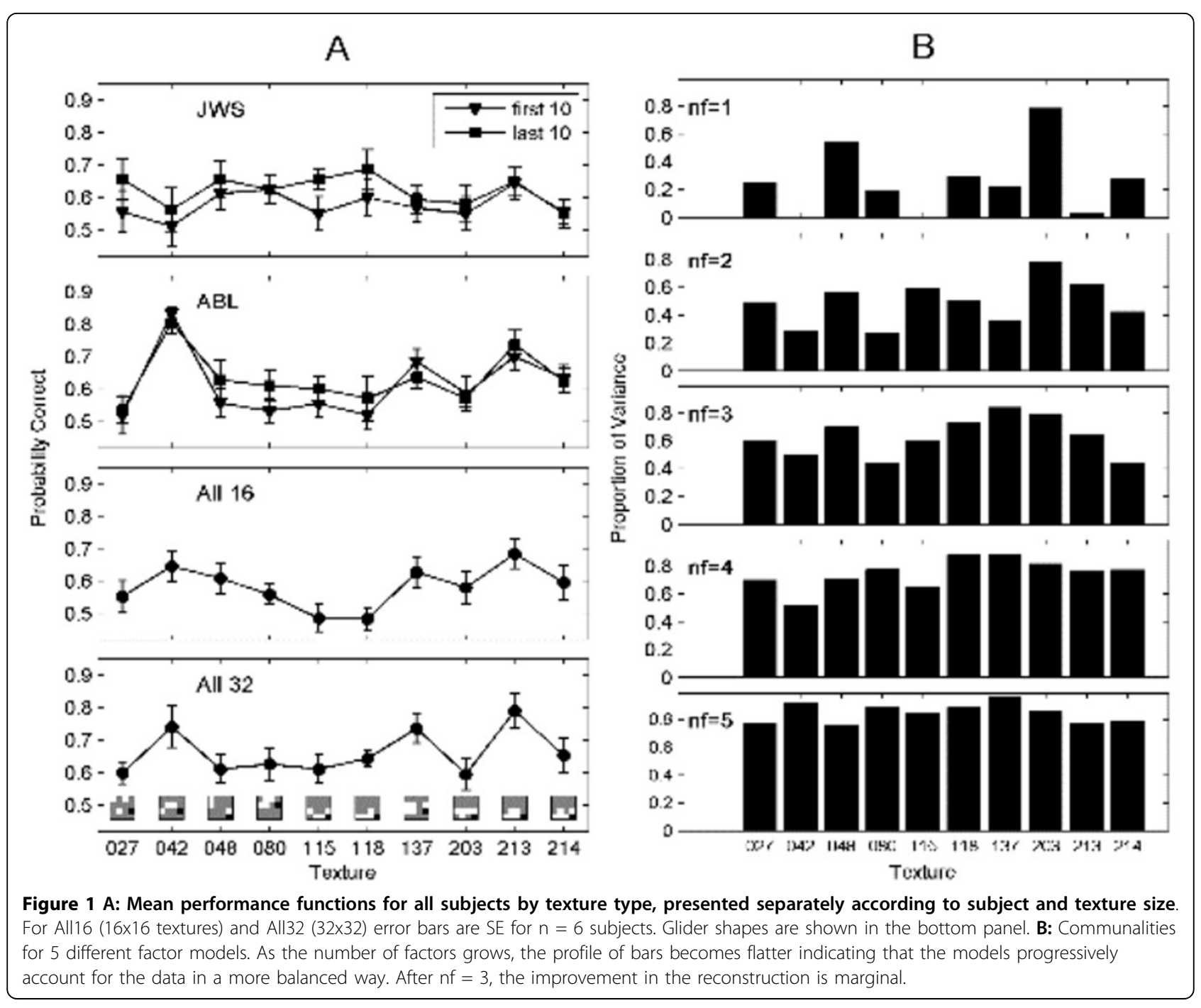

